\title{
Exploring Experiential Learning Models and developing an EL based ERE cycle in teaching at higher education in Pakistan
}

\author{
Rana Naeem Akbtar*
}

\begin{abstract}
Experiential Learning (EL) is a process where a learner learns in various phases by doing, reflecting, and experimenting (Kolb, 1984). To determine the best practices in EL, one needs to explore it by doing in-depth readings of primitive and contemporary researches and theories of EL. The current study is aimed at exploring and analyzing existing EL theories and cycles to address the needs of the local students of Pakistan. After a thorough and careful discussion, an ELbased ERE model is proposed to use EL strategies in teaching at higher education in Pakistan considering the local requirements and settings. After doing a content analysis of the relevant literature, an ERE cycle was developed that includes three phases with the basic components derived from existing prevailing $E L$ cycles. The whole process was termed as 'ERE' cycle, where 'E' referred to 'experience', ' $R$ ' referred to 'reflection' and ' $E$ ' referred to 'experiment'. This study will enable the researchers and EL practitioners to follow the strategies and activities and experiment ERE cycle in teaching different courses. The study will permit the students and teachers to experience EL strategies and have productive, meaningful, and long-lasting learning.
\end{abstract}

Keywords: Experiential Learning, ERE cycle, Teaching, Higher Education, Reflection JEL Classification: I20,I21,I23

\section{INTRODUCTION}

In the past century and especially in the contemporary 21stcentury, the Experiential Learning (EL) method has been used widely in many fields of education. The use of EL strategies in teaching has transformed the teaching practices and many types of research are being conducted around the world to experiment with the efficacy of this method and bring it in regular educational settings. Miettinen (2000) concluded that EL based method in teaching has become an established approach that is required to be further explored and utilized in the

Correspondence:

*Professor, Shaheed Zulfikar Ali Bhutto Institute of Science and Technology,naeem_faculty@hotmail.com 
paradigm of education. According to the modern-day requirements of the corporate sector, skilled employees are being sought out by the managers over those candidates who merely possess the degrees. The traditional methods have contributed sufficiently to the expansion of educational processes but they are not fulfilling the modern-day requirements. These modernday requirements demand a higher level of skills among fresh graduates when they complete their education. According to Kolb (1984) and later Kolb and Kolb $(2008 ; 2014)$ in an El process a learner learns, being involved in a learning process, by doing; thus, he develops certain skills which are part of his academic courses.

Across the globe, the impact of EL has been felt and this approach is being applied in many countries, academia, and higher education (Weil \& McGill, 1989; Boud\& Miller, 2002; Boud, Keough \& Walker2013). Miettinen (2000) has found that EL theory has two major concepts which are characterized as experience and reflection that bring learning to the top. Akhtar and Nasreen (2019) concluded that EL based education can help the students to discover their hidden skills that ultimately brings a very significant positive impact on their learning. Considering the effectiveness of EL, many higher education institutes around the globe are following EL based curriculum plans. These practices are mainly based on the EL perspectives of Dewey, Lewin, Pfeiffer, and Kolb. There exist numerous EL cycles according to the learning styles of the learners. However, in many countries, there is a scarcity of researches to explore and develop EL cycles that are based on the learning styles of the local learners in the local settings.

The rationale of this work was to investigate the existing EL theories, especially the works of Kolb (1984; 2008) and Kolb and Kolb (2014), and develop an EL cycle that could be used effectively in teaching at higher education in the local context. Since its introduction, EL theory has been appreciated by educational practitioners and advocators all over the world and in Pakistan, the reception is no different. Most of the leading business colleges claim to practice EL strategies in teaching; however, limited work has been done to evaluate the EL cycles and establish a doable learning cycle to cater to the needs of the learners and facilitators. Thus, there exists a need to understand the EL theory, explore its strategies, and develop an experiential learning cycle in the local context to improve the EL learning process in Pakistan.

\section{LITERATURE REVIEW}

Experiential learning is becoming an integral part of higher education in North America, Europe, and Australia. This theory is proposed to confront the diverse methods of education and it has marked the distinct line between the educations imparted at various levels. Though this approach is widely used in pedagogy, its significance is increasing day by day in andragogy as well (Miettinen, 2000). It has continuously been serving learners and teachers devising modern strategies and improving the educational standards of the modern era. In a recent study Prastawa, Akhyar, and Suharno (2020) have declared that the EL is effective for improving the entrepreneurial competency of vocational high school students which reflects the expanding the positive impact of experience-based learning.

The concept of EL has been widely considered over the last few decades and the shift of learning methods from teacher-centered has become the prime issue of many researchers. Traditional teaching methodologies have left students disengaged and unmotivated due to the 
teacher's highly transmissive attitude. The need to learn from one another's cooperation and real-world experiences has been immensely felt among students. Owing to this fact the work of several notable 20thcentury scholars have been put together who considered the experience a prime approach in their theories of human development and learning.

The emergence of EL theories has assisted the work of numerous eminent scholars - markedly Kurt Lewin, John Dewey, Carl Rogers, Jean Piaget, and many others to cultivate a holistic model (Kolb \& Kolb, 2005). Experiential learning serves as a comprehensive and holistic approach to the learning process. It assists the learners to utilize their abilities to get hold of the learning situation. The learners thus become much creative and more experienced and they become able to cope up with the needs of the subject and put forth their understanding and critical analysis on the subject matter. It is based on the notion of how experience enhances learning, growth, and adaptation of an individual, where students are not restricted with subjective experience in the learning process rather they gain experience through their understanding and interpretation of new information and the teacher serves as a facilitator and makes learning adaptable through a continuous reconstruction of experiences. It discourages the rote learning process and gives way to active learning. It inculcates in the student the confidence to deal with various problems in infinite ways which eventually fosters the situational skills that do not get developed through using the traditional didactic approach. Here the learner is not just a recipient of knowledge in a passive mode rather acts as an active participant who observes, analyses, evaluates, and synthesizes the information; consequently enabling the student to have a better grip of the topic with a sheer understanding of the concept. In this way, EL distinguishes itself from other learning theories and applicable not only in the formal education system but in all the decorum of life (Kolb \& Kolb, 2005).

\section{EXPERIENTIAL LEARNING CYCLES}

According to Ord (2012), EL based learning follows three major assumptions; 1. People learn best when they are involved in the personal learning experience, 2 . The knowledge develops and it is discovered by the self-efforts of the learners, 3. A person can learn the best when he sets his objectives of learning. He developed these assumptions after a thorough study of the works and cycles presented by EL practitioners especially Dewey and Kolb. Many EL scholars developed their models of the learning process which fit in the context of the specific learning environment. These cycles closely relate to one another and are based on the works of other leading EL theorists. In this study, the researcher also developed a learning cycle that is based on Kolb's (1984) EL cycle. Among some eminent cycles which are being used by the organizations, institutes, and researchers, the researcher studied most of them for his understanding and discussed and included some selected cycles and theories. Lewin (1951); Dewey (1938); Kelly (1955); Pfeiffer and Jones (1985); Juch (1983); Kolb (1984); presented EL theories and also provided EL cycles of learning. Moreover, in many other works done by these scholars they have defined the perspectives and function of EL theories. Lewin (1951) presented his EL cycle in the mid-20th century which was also referred to by Kolb (1984) for developing his four-stage cycle (Ord, 2012). Other researchers as Smith (1988); Jeffs and Smith( 2005); Blacker (2001); and Young (2006) followed and referred to the EL cycle of Kolb. Kolb (1984) discussed Lewin's theory on EL and has referred to his works in many of his research articles and books and admired how they have laid the foundation for experiential 
learning. According to Kolb (1984), Lewin's cycle highlights the elementary conflict between concrete experience and abstract concepts and the conflict between observation and action.

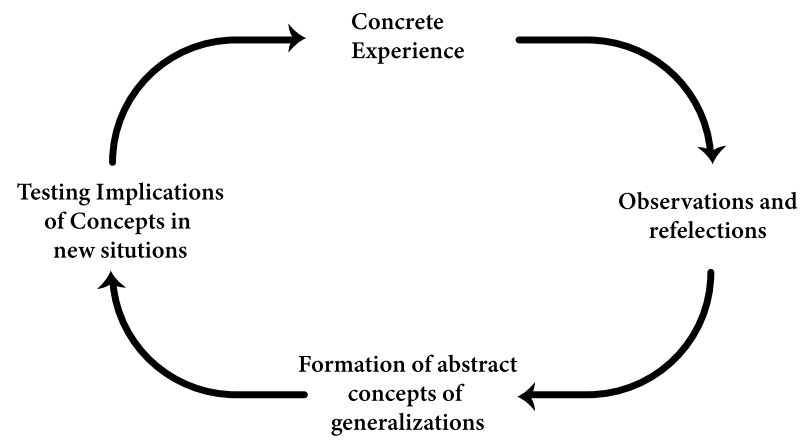

Figure1: Lewin's EL cycle (1951) as cited by Kolb (1984)

Another frequently used five staged EL cycle (See figure 2) was presented by Pfeiffer and Jones (1985) which is being followed in many universities that follow EL learning patterns. This model was developed from the EL cycle of Kolb (1984) and provided further explanation of how EL based learning can prove effective. The first phase of this cycle is to Explore and perform by putting self-efforts that does not involve any assistance from a teacher or facilitator. According to this phase, the learner may perform some individual activities or group works which can help to learn a topic or skills with personal works. In the second phase, the learner shares his experiences and observations of the first phase of learning. Then in the next phase, the learner processes learning by discussing, analyzing, and reflecting on the whole experience. The cycle moves on to generalizing the learning where the learner connects the experiences with real-world examples. The final phase of their learning process was termed application where the learner applies the knowledge in a different situation and ensures the effectiveness of his learning. This learning cycle is being used in many of the universities effectively and is serving as a model to EL practitioners.

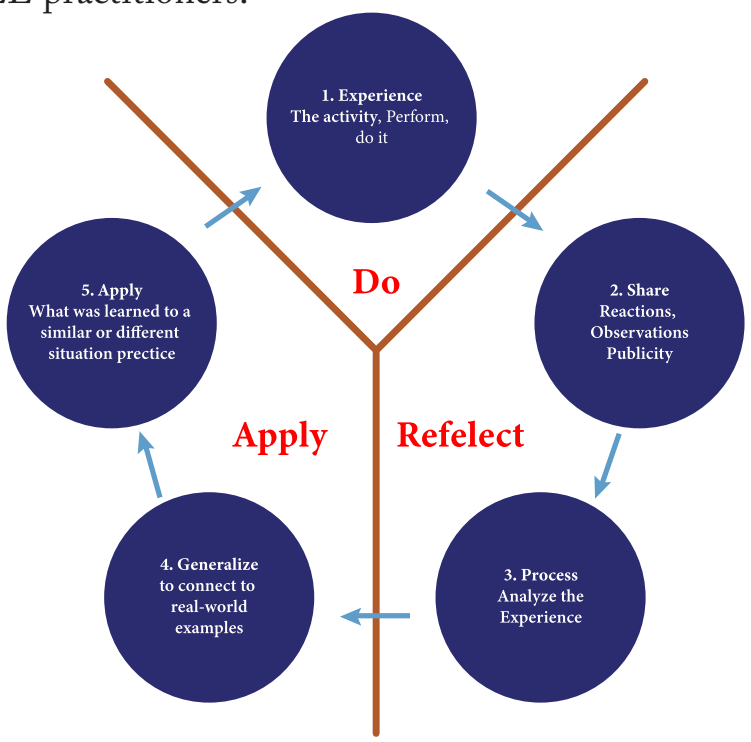

Figure 2: Pfeiffer and Jones experiential learning cycle (1985) 
A study of these cycles suggested that the process of learning in an EL model remains the same which involved the learner's involvement in which he learns the best by doing, reflecting, and experimenting. However, the researcher discussed in detail the EL concept of Dewey and Kolb are the pillars of EL based learning.

\section{KOLB'S EXPERIENTIAL LEARNING CYCLE}

Kolb (1984) presented his theory on EL and four staged cycles that were directly influenced by the works of Dewey's $(1916 ; 1986)$ EL theories. However, many contemporary researchers of EL took the research works of Kolb (1984) and Kolb and Kolb (2005) for their study on experiential education. Smith (1988) specified that his educational practices and theories followed the model of Kolb (1984). He discussed the works of Dewey and Kolb in detail and after critical analysis declared that Kolb's (1984) model was one of the most appropriate models presented on experiential education. Likewise, Blacker (2001) also claimed that Kolb's four-stage cycle was very effective and useful in applying experience in education. Another scholar Young (2006) also endorsed the importance and significance of Kolb's work, which has been proved in the experiential study. Merton and Wylie (2002) have also stated similar kind of remarks on the usefulness of Kolb's EL model in the study. Smith (1994) went on further to declare Kolb's model as an exclusive learning model that can serve the experiential learning process. Jeff and Smith (2005) regarded this model as a simple and comprehensive way to understand and conceptualize the process of experiential learning. These studies explicitly reflect that how important are the works of Kolb and later on Kolb and Kolb for the practitioners and students of experiential learning. To understand the significance of the EL process, these works are role model and guide to apply and develop further strategies to make them as effective in the local context.

Kolb and Kolb (2005) advocate learning as the procedure whereby information is made through the change of experience. The mixture of grasping and changing of experience results in the form of knowledge. Kolb's (1984) experiential learning theory (see Figure 4) depicts two argumentatively related methods of grasping experience which are a) Concrete Experience (CE) and b) Abstract Conceptualization (AC) and two argumentatively related methods of changing inexperience are a) Reflective Observation (RO) and b) Active Experimentation (AE) (Kolb $\&$ Kolb, 2005). According to Kolb, EL is a process that provides creative tension among four learning modes that is receptive to the specific context. This process is represented as a learning cycle where students encounter each of four areas; experiencing, reflecting, thinking, and acting. This recursive process is effective for every individual that stimulates their learning experience and what is being learned. Actual and concrete experiences provide ground to the observation and reflections. These reflections are then absorbed and derived into unique ideas from which new implications for activity can be extracted. These implications are then utilized for dynamic assessment which prompts new concrete experiences. The learning process can take place at any point in time where the learner encounters real experiences that results in gaining new abstract ideas. This process encompasses learners in acquiring real experiences and continues collecting information. This enhances their reflective learning and critical thinking. 


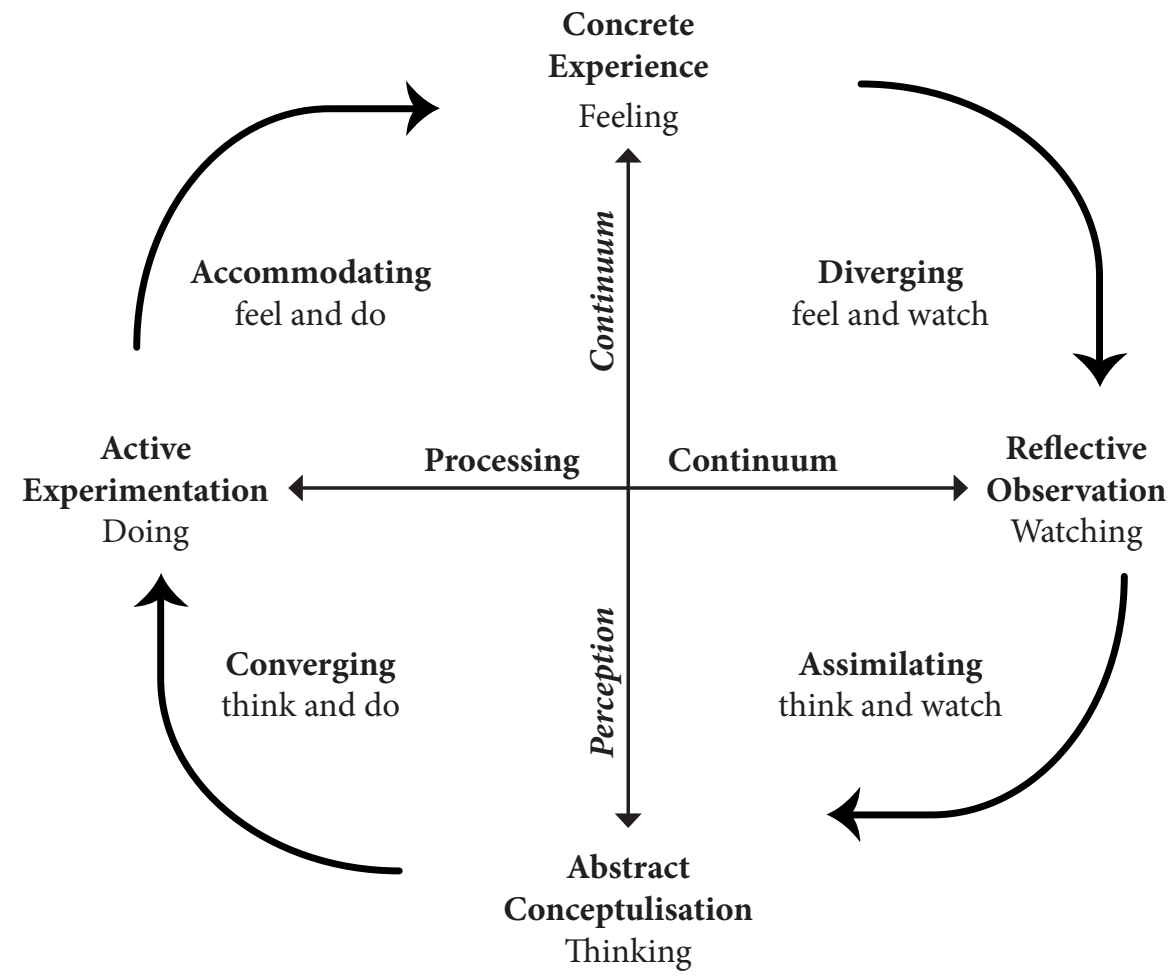

Figure 3: Kolb's experiential learning cycle

Experiential learning through classroom activities and projects has played an essential role in facilitating business education. These activities are reinforced through enactment games and role play. A study by Kralj (2005) endeavors to constitute experiential learning practices through simulation methods. The study requires to be enacted in an organizational setting where participants are administered by a set of rules to follow a formulated game plan. The purpose of this roleplay is to make participants act in a real-life business situation. The game has been played in a competitive environment with rigid rules where dynamic organizational processes are projected by computer-assisted enactment which later determined achieved results. Kralj also manages to constitute an environment where free form games have played. The purpose of these games is to create a learning environment where participants are not restricted to take any action for it helps them in decision making, solving managerial problems, and self-organizing themselves (Kralj, 2005).

These games have resulted in the foundation of operational research that is followed by the advancement of reinforcing business games and war games. The foundation of the real business game was put forward in the USA in 1956. America's Management Association formulated the Top Management Simulation. The game is comprised of several components such as research, market, development activities and production, etc. Herz and Merz (1998) presented interesting experiential exercises in teaching economics. They attempted to examine the impact of enactment games in economics by improvising the experiential learning model designed by Kolb (1984). A game named MACRO was employed in this study which characterized four groups of economic individuals; government, business, the central bank, and union. The goal of that game was to achieve a controlled guideline for specific decision making in a country. 
The results demonstrated that as opposed to lecture-based methodologies the game had influenced the participants in a better way by employing Kolb's (1984) EL model. This game accommodated participants to evaluate the economic challenges of every individual which include establishing the economic foundation and framing flexible simulation according to the need of the individuals and their environment (Herz\&Merz, 1998).

Further, the researcher, in this study followed most of the characteristics specified by Chapman et al. (1995) that he suggested being included in any EL process.

\section{EL BASED ERE CYCLE}

The literature review provided an in-depth understanding of the EL process and its function. Using content analysis in the paradigm of qualitative research, the researcher tried to develop a practical EL based learning cycle to fulfill the needs of the local students. The need to develop this cycle emerged from the limitations and different classroom setting locally as compared to the other developed countries. The existing cycles enabled the researcher to recognize the three major phases in an EL process, and after reading numerous theories of prominent EL scholars, these three phases are; experience, reflection, and experiment. The whole process was termed as 'ERE' cycle, where 'E' referred to 'experience', 'R' referred to 'reflection' and 'E' referred to 'experiment'.According to Kolb (1984) and Pfeiffer and Jones (1975), experience comes in the first place in any EL process. Kolb (1984) defined the EL process is the combination of grasping and transforming experience into knowledge. Kolb's model of EL includes four stages, whereas the ERE cycle has only three phases considering the essence of an EL process which these three phases can cover in the context of Pakistan. The other prominent models have presented and followed three to five stages of an EL process; however, after careful study of all those cycles, it was considered that these three phases will suffice to successfully achieve the spirit of any EL process. Figure 4 shows that the ERE cycle has included all the major components of Kolb's EL process and other existing EL cycles.

Figure 4: ERE Cycle

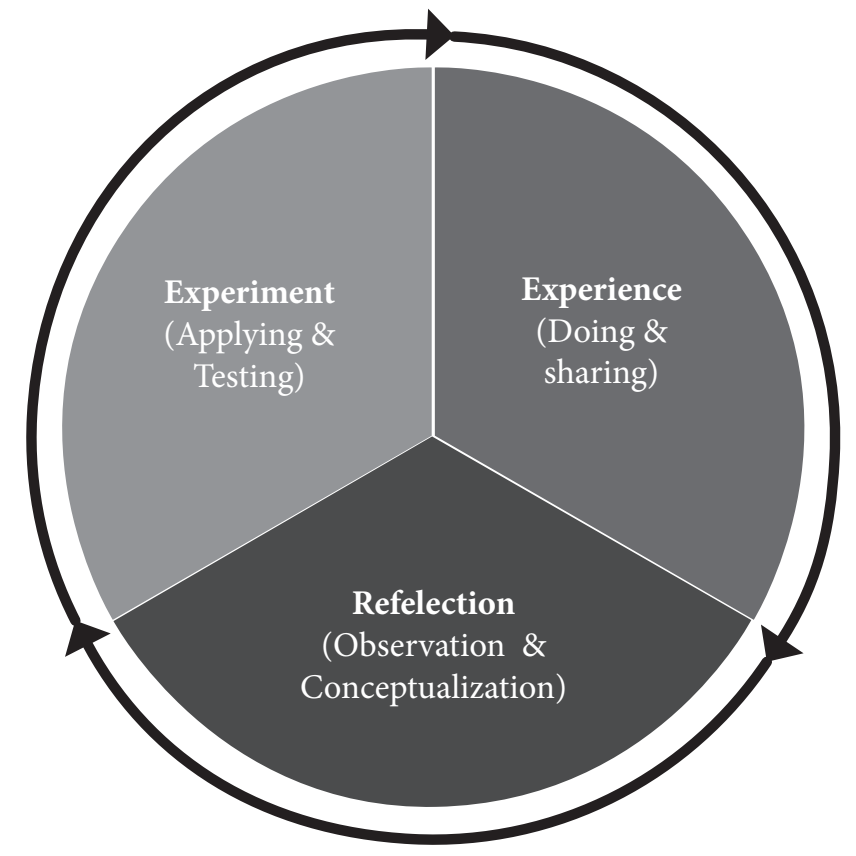




\section{EXPERIENCE}

Experience has been the major component in all the EL models as it typically defines the term Experiential Learning. Without doing and experiencing any learning task, the EL process cannot be initiated. Most of the scholars and their theories including the pioneer theories of Dewey and the works of Kolb and Kolb have emphasized the importance of experience. The first step of this cycle was named 'experience' which demanded reflective and preparatory practices as it emphasized concrete experiences in order to assess abstract conceptualization. The first phase would be very vital to uncover and utilize the prior experiences of the learners to further build knowledge on the existing knowledge. This kind of learning that starts from experiences is a natural way of learning which has been pointed out by (Howle, 1980 as cited in Smith, 2001). This phase would require the learners to participate in a learning process utilizing their prior experiences. Many studies on EL have recommended the utilization of experiences to learn and succeed in personal and professional life (Sims 1981; 1983).

Kolb's (1984) model of experiential learning defines that we learn from our life experiences and the first step of his cycle (1984) was also termed as 'concrete experience'. He claimed that individuals learn from everyday experiences which can be educational and professional. In most of the EL theories and cycles, the researchers emphasized the involvement of learners' prior experiences in any on the hand learning process. The renowned EL scholars including Lewin, Piaget, Dewey, Pffiefer, Kolb, and Kolb and Kolb discussed that learners' experiences are the spirit of any EL practices. The credibility of experience and its presence in an EL process has been discussed with related literature review in detail in chapter two.

The students at the graduate and undergraduate level learn numerous things in their academic careers. Many students at the graduate level also work as professionals and learn a great deal from their workplace. The facilitators can aim at utilizing those experiences effectually and construct new knowledge based on those academic and professional experiences. To extract best from that previous knowledge of the students, there can be devised useful strategies that would help the learners to bring in their own experiences in the learning process.

When a student comes with prior knowledge, it helps him in maintaining a strong foundation for building new information and interprets what he has already learned. Thus, his prior experience proves vital during an ongoing learning process. Students tend to make connections between their chunks of knowledge they are acquiring and experiences that they have gained earlier. These connections get transformed into knowledge structures that have been productively developed. In this way, students can restore their knowledge and apply it accurately and effectively. Experience and learning can be best enhanced if students engage themselves in gaining practical experience during their learning process that aims at the fulfillment of any practical criteria or goal and targets any specific challenge that would meet the performance criteria. A learner can learn best and reap the influential reward by spending time on it, once he or she knows the art of reflecting upon his or her own experiences. Moreover, reflecting upon experiences lead to an improvement in problem-solving ability. It has been proposed in many above mentioned researches that the designated goals can be achieved once when the focus is on self-efficacy. An ability to personally evaluate oneself in order to develop and execute courses of action may help in attaining desired outcomes. 
To inculcate learners' prior experience in their on-hand learning process, many procedures can be adopted in Pakistani traditional and non-traditional classrooms. In this study, the researcher has given an example of how to include experiences in these classrooms by involving the learners in pre-class activities. These pre-class activities could be designed in such a way that learners could recall their previous knowledge and could utilize it in a fresh learning experience. Group learning can be one of the essences of experiential learning that could be exploited in extracting the experiences of the participants. These groups in pre-class activities can be formed and used in different ways applying various activities. There were a few key components that were identified by the researcher while analyzing literature on activities in an EL classroom that could be employed to involve these groups in pre-class activities. However, there is a possibility of many more interesting EL activities that could be explored and utilized in the first phase of the ERE cycle.

1. The foremost factor which can be exploited in the first phase of the ERE cycle is the prior knowledge 'experience' of every learner on the topic he is learning. Learning is always constructed on the previous knowledge of any learner and he relearns the things from earlier learning. For example, in communication courses at higher education, the content is based on students' background knowledge of the topics he has studied before. Similarly, at the masters' level, many students are involved in professional work. They are involved in written communication by writing letters, memos, reports, and oral communication by appearing in interviews, meetings, and presentations. These practices are regular at business places and parttime business students usually have very good experience of these topics. In communication courses, most of the topics relate above mentioned written and oral communication skills. The teacher can involve the students to share with their team members what they already know and discuss different perspectives and their understanding of the topic. This would help him to share and listen to what other team members know and ultimately lead him to gain an understanding on the topic before coming to learn in the class. This sharing activity can easily be performed using social networking sights (SNS) where students can share and discuss the topics. In this study, the students formed their closed groups on SNS and actively participated and shared their prior knowledge with team members. SNS can play an important role in sharing students' experience on any topic and this fact has been established in many studies. Akhtar and Tuba (2015) recommended the use of SNS to enhance students learning skills. The discussion would help them a great deal to learn from their team members and enhance their knowledge on the given topics which they were supposed to learn in their classes. This activity would help the learners and facilitators to get an opportunity to run an active learning process in the class as the students would be well prepared and would have shared their knowledge in an active discussion in classroom learning.

1 To involve students in research-based and analytical reading can be applied in pre-class learning activities. When students share their personal knowledge with their team members, they can be asked to share a few references from research works or books on the topic. This activity can be highly effective in many ways. It would not only help the students to start reading from the books and research papers, which is becoming a forgetting practice but would also allow them to analyze others' shared work and learn from them. The active discussion by the team members on the works they would share could prove very useful for the next stage of the learning process. 
2 Students can also learn through observation while involving themselves in preclass activities. The learners with little on hand knowledge can get an opportunity to observe and learn while other team members share their personal experiences and academic and professional knowledge. In this way, even if they don't have their prior experiences on the topic they would have a worthy prospect to gain some knowledge which will prove useful in participating in classroom activities in the next phase of the ERE cycle.

\section{REFLECTION}

Kolb's (1984) EL cycle demonstrated "reflection" as a key component in his learning process. In the researcher's developed ERE cycle, reflection comes after the first phase that was supposed to explore and include learners' prior experiences. Reflection is an essential phase of any EL process and this fact has been endorsed by almost all the EL practitioners and they have emphasized using reflections to learn from the experience stage. Dewey $(1897 ; 1917 ; 1938)$ firmly believed that without a reflection phase learning never occurs. Refection on getting or going through an experience would help the learner to improve and perform better in the new learning experience. Other notable EL practitioners as described in the literature always declared the fact that reflection is an integral part of any learning process and the absence of this phenomenon would not complete a learning process. Pfieffer and Jones (1985) in their EL cycle have also put the part of reflection as one of the phases of the process. Schon (1983) another advocate of EL practices also endorsed Dewey's views of the role of reflection in a learning process.

In experiential learning activities, many strategies and activities can be devised to include reflection in the learning process. Moreover, these reflections assisted to form the themes at the end of this research. Many studies have been carried out to determine a variety of classroom activities that can also be used during the in-class learning phase. Paul and Mukhopadhyay (2005) examined classroom activities including website development, role-play, guest speaker sessions, the class project including negotiation, and showing videos comprehensible for students in resolving issues of international business. These activities would help a great deal in incorporating effective learning skills through reflections in the students. It can create a learning environment where participants would not be restricted to be passive learners and would help them in decision making, solving managerial problems, and self-organizing. Mostly, a learner would develop an interest when some stimulus or inciting activities would be performed in the classroom. These activities would serve the learners to ponder on what they have learned and whether they have achieved the intended learning objectives of the topic being learned.

Active and genuine learning can be promoted in a learning process when the students are asked to reflect upon their learning experiences through both oral and written communication. Managers who are effective in this stage emphasize understanding as opposed to practical application, a concern with what is true or how things happen as opposed to what is practical, an emphasis on reflection as opposed to action (Kolb \& Kolb, 2009). Thus, the reflection phase would help the learners to analyze the learning and learning process; drafting letters and reports doing role-plays and improve them in conveying issues which they were unable to express in words or while performing activities; presentations one to one competition on different topics which would boost up their confidence and motivated them towards active participation; role-play; meeting; interviews that would allow students to act in real-life scenarios and gain 
demonstrable experiences; public speaking in front of real-life audiences such as in auditorium, public places or research place. At the end of every learning experience, students would be asked to share their learning experience by laying out their written feedback and reflection. These reflections would help the facilitators to form further learning activities using EL strategies. Reflections would also enable the researcher to understand the barriers and fix the issues which learners would be facing during the experiment.

\section{EXPERIMENT}

Experimentation is an essential part of any experiential learning model. Although the developed ERE cycle remains an ongoing process, its final step was termed 'Experiment'. This phase would enable the learners to apply whatever they learned during the whole process. In a classroom setting; the final projects, exams, and internships could prove helpful to assess the newly learned skills among the learners. EL models mainly focus on developing the skills among the learners and this proposed cycle has mainly focused on helping teachers to develop their students' skills which are chiefly desired by the corporate sector when they hire fresh graduates. According to Kolb (1984), the phase of experimentation is vital to test and evaluate the whole learning process. Undoubtedly, only an efficacious demonstration of any learned skills in true situations can hold whether a learning process was a success.

Summing up, learning from our experiences involves the key element of reflection. Most people don't theorize about their learning in this way, but in their learning follow Kolb's cycle without knowing it. There may be devised many strategies to involve students in experimentation; however, there could be developed some practical EL strategies considering the limitations of different classroom settings that can be performed conveniently in the context of this study. In the present research, the last stage of the experiential learning cycle would deepen student understanding for it would foster a better comprehension of the material. This final step would hone students' professional skills and enhances their future performance.
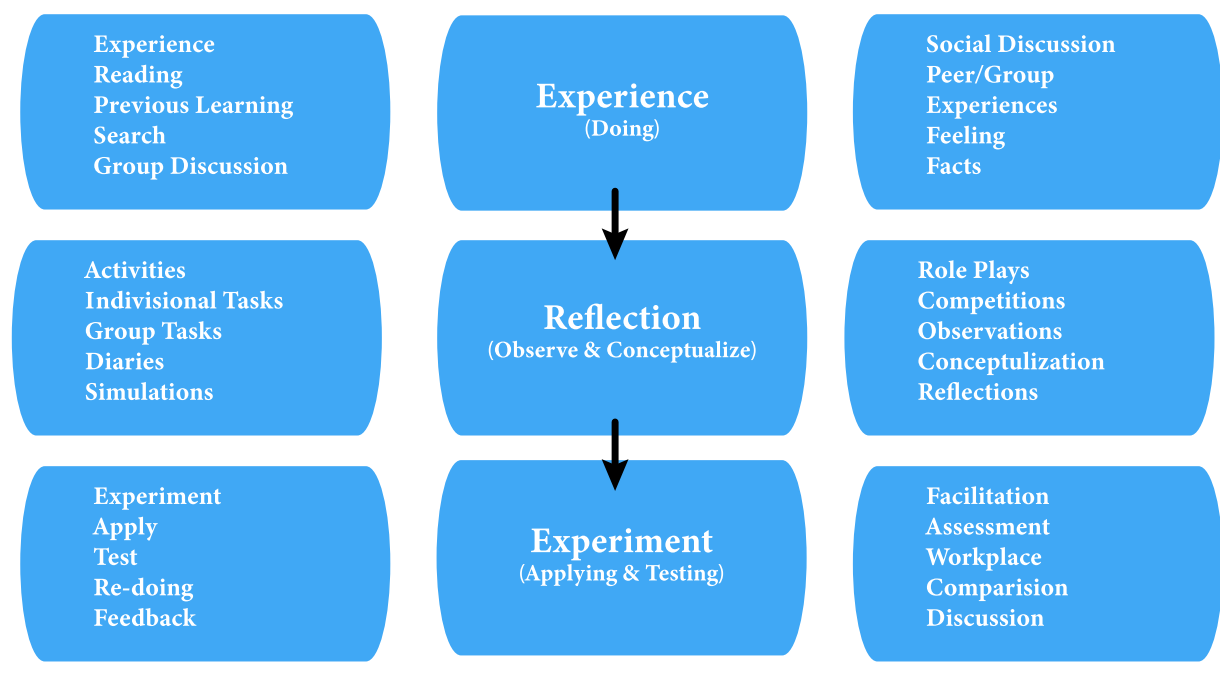

Role Plays

Competitions

Observations

Conceptulization

Reflections

Facilitation

Assessment

Workplace

Comparision

Discussion 
Previously, there has been conducted very few researches that explored or tested the effectiveness of EL in the field of business education in Pakistan and its impact on business communication courses (Akhtar, 2019). Recently in Pakistan, Javed (2015); Noman (2018), and Akhtar (2019) have conducted their Ph.D. researches to explore the effectiveness of EL in business education. However, there has been found no direct research that has served or explored the guidelines for applying EL theory in teaching communication courses in the local context. Owing to this fact, the present study served its purpose and accommodated an EL based ERE cycle that can be used in teaching at higher education. Botha (2004) found evidence that experiential methodologies may, at least to some extent, be used to address some of the concerns regarding current business education and the same can be done for most of the educational courses.

Incompetency in employing modern teaching techniques effectively was one of the foremost reasons which became the barrier for all the fresh graduates who enter into their professional life. It was felt a dire need to investigate and propose a model that can cater to the needs of the local EL practitioners.

The current study endeavored to investigate current and previous experiential learning models that are being used around the world. These models were not designed to cater to the needs of the students in Pakistan due to the learning environment and different policies as compared to those countries. The foundation of the proposed ERE model is derived from those universally practiced models, however, this is considered and directed to suit and fit in the local settings of higher education. Numerous methodologies and teaching strategies have been formulated and designed using the EL framework of Kolb (1984), Dewey (1938), Lewin (1957), and Jarvis (1993) which can help teachers to implement, design, and improve their teaching techniques in order to strike contemporary styles of teaching. Students who would be taught using the ERE cycle might get more benefits from it in improving and enhancing their professional skills and capabilities.

\section{RECOMMENDATIONS}

1 EL practitioners can use the ERE model as a stepping stone towards introducing EL the approach in their teaching

2 The ERE cycle can further be studied, evaluated, and modified according to the existing policies of higher education in Pakistan.

3 ERE cycle can be further tested to see the effectiveness of this model.

4 More studies can be conducted to explore the learning experiences of the students and teachers at a different level and places which will help to further improve this model.

5 This model can be used and tested at other levels of education which will inculcate the EL culture in Pakistan. 


\section{REFERENCES}

Akhtar, N., \& Tuba, N. (2015) Using Social Networking Site (SNS) in Students' Learning Experiences: An Experimental Study at Higher Secondary School Karachi, Pakistan. International Journal of English and Education. 4(3), 464-476.

Akhtar, N (2019). Exploring and testing ERE cycle in teaching business communication courses (Doctoral dissertation, Institute of Business Management, Karachi, Pakistan). Retrieved from https://www.iobm.edu.pk/thesis/department-of-education/

Akhtar, N., \& Hussain, N. (2019). Testing ERE Cycle in Teaching Business Communication Courses: Experiential Learning Strategies. Journal of Education and Educational Development, 6(1), 62-77.

Blacker, H. (2001) Learning from experience. In L. Deer Richardson and M. Wolfe (Eds.) Principles and Practice of Informal Education (London: RoutledgeFalmer).

Botha, R. J. (2004). Excellence in leadership: demands on the professional school principal. South African journal of education, 24(3), 239-243.

Boud, D., \& Miller, N. (2002). Synthesizing traditions and identifying themes in learning from experience. In Working with experience (pp. 26-36). Routledge.

Boud, D., Keogh, R., \& Walker, D. (Eds.). (2013). Reflection: Turning experience into learning. Routledge.

Boyatzis, R. E., \& Kolb, D. A. (1991). Assessing individuality in learning: The learning skills profile. Educational Psychology, 11(3-4), 279-295.

Boyatzis, R. E., Baker, A., Leonard, D., Rhee, K., \& Thompson, L. (1995). Will it make a difference? Assessing a value-based, outcome oriented, competency-based professional program. Innovating in professional education: Steps on a journey from teaching to learning. San Francisco: Jossey-Bass.

Chapman, S., McPhee, P., \&Proudman, B. (1992). What is experiential education?. Journal of Experiential Education, 15(2), 16-23.

Dewey, J. (1897). The significance of the problem of knowledge (3rd Ed.).University of Chicago Press.

Dewey, J. (1917). Learning to earn. School and society, 5(4), 331-335.

Dewey, J. (1986). Experience and education. In The Educational Forum (Vol. 50, No. 3, pp. 241-252). Taylor \& Francis Group.

Herz, B., \&Merz, W. (1998).Experiential learning and the effectiveness of economic simulation games. Simulation Eं Gaming, 29(2), 238-250. 
Jeffs, T. and Smith, M. K.(2005) Informal Education, conversation, democracy and learning (3rd Ed.Turnaround.https://www.amazon.com/Informal-Education-Conversation-Democracy-Learning/dp/1900219298

Juch, B. (1983). Personal development: Theory and practice in management training. Wiley.https:// www.amazon.com/Personal-Development-Practice-Management-Training/dp/0471104582

Kelly, C. (1997). David Kolb, the theory of experiential learning and ESL. The Internet TESL Journal, 3(9), 1-5.

Kolb, A. Y., \& Kolb, D. A. (2005). Learning styles and learning spaces: Enhancing experiential learning in higher education. Academy of management learning Ev education, 4(2), 193-212.

Kolb, A. \& Kolb, D. (2009). Experiential learning theory: a dynamic, holistic approach to management learning, education and development. In S. J. Armstrong \& C. V. Fukami., The SAGE handbook of management learning, education and development (pp. 42-68). London: SAGE Publications Ltd. DOI: 10.4135/9780857021038.n3

Kolb, A. Y., \&Kolb, D. A. (2009). The learning way: Meta-cognitive aspects of experiential learning. Simulation E Gaming, 40(3), 297-327.

Kolb, A. \& Kolb, D. (2012). Experiential Learning Theory, in Encyclopedia of the Sciences of Learning. In Norbert M. Seel.,Encyclopedia of the Sciences of Learning (pp. 1215-1219). Springer US. DOI: 10.1007/978-1-4419-1428-6

Kolb, D. (1984) Experiential Learning, Experience as the Source of Learning and Development, (2nd Ed.). Prentice-Hall.http://ptgmedia.pearsoncmg.com/images/9780133892406/samplepages/9780133892406.pdf

Kralj, J. (2005). Case study and related experiential teaching methods in non-case environments: the Slovenia experience.

Lewin, K. (1944). The dynamics of group action. Educational leadership, 1(4), 195-200.

Lewin, K. (1951). Field theory in social science.Life Long Education. Volume 28 IV.

Lewis, L. H., \& Williams, C. J. (1994). Experiential learning: Past and present. New directions for adult and continuing education, 1994(62), 5-16.

Mainemelis, C., Boyatzis, R. E., \& Kolb, D. A. (2002). Learning styles and adaptive flexibility: Testing experiential learning theory. Management learning, 33(1), 5-33.

Merton, B., \& Wylie, T. (2002). Towards a Contemporary Curriculum for Youth Work. National Youth Agency.

Miettinen, R. (2000). The concept of experiential learning and John Dewey's theory of reflective thought and action. International Journal of Lifelong Education, 19(1), 54-72. 
Ord, J. (2012). John Dewey and Experiential Learning: Developing the theory of youth work. Youth E Policy, 108, 55-72.

Paul, P., \&Mukhopadhyay, K. (2005).Experiential learning in international business education. Journal of Teaching in International Business, 16(2), 7-25.

Pfieffer, J. W., \& Jones, J. E. (1979). The Reference Guide to Handbooks and Annuals (1st Ed.). San Diego, CA: University Associates Published and Consultants.https://www.amazon.com/Reference-Handbooks-Annuals-William Pfeiffer/dp/0883900696

Schon, D. A. (1983). The reflective practitioner: How professionals think in action (1st Ed.). New York: Basic books.

Prastawa, S., \&Akhyar, M. (2020). The Effectiveness of Experiential Learning Based on Creative Industry to Improve Competency of Entrepreneurship of Vocational High School Students. In 3rd International Conference on Learning Innovation and Quality Education (ICLIQE 2019) (pp. 25-33). Atlantis Press.

Sims, R. R. (1981). Assessing competencies in experiential learning theory: A person-job congruence model of effectiveness in professional careers. Unpublished $\mathrm{Ph}$. D. dissertation. Case Western Reserve University..

Sims, R. R. (1983). Kolb's experiential learning theory: A framework for assessing person-job interaction. Academy of Management Review, 8(3), 501-508.

Smith, J. (2002). Learning styles: Fashion fad or lever for change? The application of learning style theory to inclusive curriculum delivery. Innovations in Education and Teaching International, 39(1), 63-70.

Smith, P. A. (2001). Action learning and reflective practice in project environments that are related to leadership development. Management Learning, 32(1), 31-48.

Weil, S. W., \& McGill, I. (1989). Making sense of experiential learning: Diversity in theory and practice. Open University.

Wurdinger, S. D. (2005). Using experiential learning in the classroom: Practical ideas for all educators. Lanham, MD: Scarecrow Education. 